\title{
Building Back Better
}

\author{
Tania Mysak
}

DOI: 10.4212/cjhp.v74i3.3159

Forgive the cliché of the title, and as the last months of my presidential term approach, allow me to offer some parting thoughts on what the Canadian Society of Hospital Pharmacists (CSHP) can focus its efforts on in a postpandemic world.

I write this in the interregnum of a hugely successful Together conference and a preventable (and predictable) third wave of COVID-19 in our most populous provinces. It is an interesting place, in time and space, to reflect on how lessons are learned (or not) and how this past year will shape our future for years to come.

As I wrote a year ago, COVID-19 has been the great disruptor in our lives, personally, professionally, and within our Society. Our traditional revenue sources, manner of conducting business, and networks have been upturned in ways that are unlikely to return to pre-2019 norms. CSHP, like so much else, will require a "new normal".

What have we learned in the past year that will guide us on our journey to this future state?

First, conferences. For decades, our Professional Practice Conference served as an annual gathering to learn, network, and frankly, generate a significant amount of revenue for the Society. However, over the past decade, we have seen a steady decline in sponsorship and participation, and the resultant revenues have declined accordingly. Banff Conference (held by our Western Branches) has had similar declines in attendance. COVID-19 has thrown the future of in-person conferences into question. Will they be as large and encompassing? Do they need to be in person?

As we gathered online for Together, we received amazing feedback about the content (CSHP consistently hosts excellent content) and received kudos for accessibility. Several members took the time to reach out and note how the online format made attendance possible for them, whereas previously, they were unable to attend. This feedback is critical because it addresses something we have focused on in our Strategic Plan (https://cshp.ca/document/4123/CSHP -Strategic-Plan-2020.pdf)-member value. If our members value the ability to access this kind of excellent learning and networking opportunity, we would be remiss in not considering that in our plans.

Of course, as it has in all things, COVID-19 has also amped up our online networking, as witnessed by the increased level of engagement on our Pharmacy Specialty Networks. We were able to build on this momentum by including more webinars, having a stronger social media presence, and using every engagement and gamification tool available to us on our online conference platform.

Ultimately, we know that one of the most powerful reasons our members value CSHP is for the networking and sense of family that belonging brings. In a period that has taught us the value of community, CSHP is committed to continuing to foster those connections and friendships that have united and strengthened us over the past year. We understand that this takes in person human connection, and we remain resolved that those contacts will remain a vital part of our Society for years to come.

We can't wait to see all of your faces again at our local and national events.

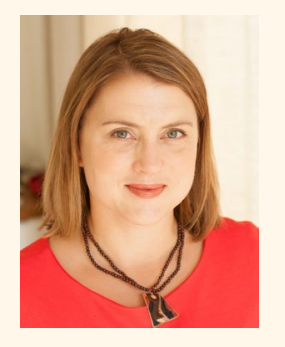

Tania Mysak, BSP, PharmD, is Past President and Vision Liaison for the Canadian Society of Hospital Pharmacists. 